\title{
Oestrogen inhibits resveratrol-induced post-translational modification of p53 and apoptosis in breast cancer cells
}

\author{
S Zhang ${ }^{1,4}$, HJ Cao ${ }^{1,4}$, FB Davis ${ }^{*, 1}$, H-Y Tang ${ }^{2}$, PJ Davis ${ }^{1,2,3}$ and H-Y Lin ${ }^{2}$ \\ 'The Ordway Research Institute, 150 New Scotland Avenue, Albany, NY 12208, USA; ${ }^{2}$ The Research Service, Stratton Veterans Administration Medical \\ Center, 113 Holland Avenue, Albany, NY 12208, USA; ${ }^{3}$ The Wadsworth Center, New York State Department of Health, Empire State Plaza, Albany, NY \\ I220I, USA
}

Resveratrol, a naturally occurring stilbene, induced apoptosis in human breast cancer MCF-7 cells. The mechanism of this effect was dependent on mitogen-activated protein kinase (MAPK, ERKI/2) activation and was associated with serine phosphorylation and acetylation of $p 53$. Treatment of MCF-7 cells with resveratrol in the presence of $17 \beta$-oestradiol $\left(E_{2}\right)$ further enhanced MAPK activation, but $E_{2}$ blocked resveratrol-induced apoptosis, as measured by nucleosome ELISA and DNA fragmentation assays. $E_{2}$ inhibited resveratrol-stimulated phosphorylation of serines 15, 20 and 392 of p53 and acetylation of p53 in a concentration- and timedependent manner. These effects of $\mathrm{E}_{2}$ on resveratrol action were blocked by $\mathrm{ICI} I 82,780(\mathrm{ICl})$, an inhibitor of the nuclear oestrogen receptor- $\alpha$ (ER). ICI I82,780 did not block the actions of resveratrol, alone. Electrophoretic mobility studies of p53 binding to DNA and of $p 21$ expression indicated that $E_{2}$ inhibited resveratrol-induced, p53-directed transcriptional activity. These results suggest that $\mathrm{E}_{2}$ inhibits p53-dependent apoptosis in MCF-7 cells by interfering with post-translational modifications of p53 which are essential for p53-dependent DNA binding and consequent stimulation of apoptotic pathways. These studies provide insight into the complex pathways by which apoptosis is induced by resveratrol in $\mathrm{E}_{2}$-depleted and -repleted environments. British Journal of Cancer (2004) 91, 178-185. doi:10.1038/sj.bjc.6601902 www.bjcancer.com Published online 8 June 2004

(c) 2004 Cancer Research UK

Keywords: breast cancer; MCF-7 cells; p53; resveratrol; oestrogen; apoptosis; mitogen-activated protein kinase

Resveratrol is a phytoalexin that occurs naturally in grape skin and several medicinal plants (Jeanet et al, 1991; Lu and Serrero, 1999). It has anticancer (Jang et al, 1997) and other biologic properties (Pace-Asciak et al, 1995). The mechanism of the antitumour effect of resveratrol is not well understood, but in some tumour cell models induction of apoptosis is involved (Clement et al, 1998; Huang et al, 1999; She et al, 2001). We have demonstrated resveratrol-induced apoptosis in four thyroid cancer cell lines (Shih et al, 2002) and two prostate cancer cell lines (Lin et al, 2002). Resveratrol has been shown to exert mixed oestrogen agonist/antagonist activities in mammary cancer cell cultures, but in the presence of $17 \beta$-oestradiol (oestradiol, $\mathrm{E}_{2}$ ), resveratrol may function as an antioestrogen (Bhat et al, 2001), antagonising $\mathrm{E}_{2}$ activities. In this study, we have explored the effects of resveratrol and $E_{2}$, both separately and together, in breast cancer (MCF-7) cells, and show that $\mathrm{E}_{2}$ inhibits resveratrol-induced apoptosis in these cells.

p53 is an oncogene suppressor protein that is present at low levels in normal cells (Higashimoto et al, 2000). In response to a variety of stresses, including DNA damage (Higashimoto et al, 2000 ), levels of cellular p53 protein rise; this increase in p53 results at least in part from a post-translational mechanism that stabilises the protein (Ashcroft and Vousden, 1999). p53 can adopt two

*Correspondence: Dr FB Davis; E-mail: fdavis@ordwayresearch.org

${ }^{4}$ These authors contributed equally to this work

Received 23 January 2004; revised 14 April 2004; accepted 19 April

2004; published online 8 June 2004 forms in vitro, a latent form that binds naked DNA poorly and an active form that binds to DNA well. Conversion of the latent form to the active form is thought to occur by an allosteric mechanism conditioned by phosphorylation and acetylation (Sakaguchi et al, 1998; Liu et al, 1999; Prives and Manley, 2001). Serine phosphorylation of wild-type p53 at different sites has different biological consequences (Agarwal et al, 1998). We and others have shown that resveratrol-induced serine phosphorylation of p53 in various cancer cells is essential to resveratrol-induced apoptosis (She et al, 2001; Lin et al, 2002; Shih et al, 2002). Acetylation of p53 occurs in the wake of serine phosphorylation and is essential for p53-dependent gene expression (Berlev et al, 2001). In this report, we show that although both $\mathrm{E}_{2}$ and resveratrol stimulate mitogenactivated protein kinase (MAPK; ERK1/2) activity in an additive manner in MCF-7 breast cancer cells, $\mathrm{E}_{2}$ inhibits resveratrolinduced serine phosphorylation and acetylation of p53, as well as oligonucleotide binding of $\mathrm{p} 53$. As a result, resveratrol-induced p53-dependent $p 21$ gene expression and apoptosis are inhibited by $\mathrm{E}_{2}$ in these breast cancer cells.

\section{MATERIALS AND METHODS}

\section{Cell lines and reagents}

The MCF-7 human breast cancer cells were provided by Dr J Bennett (Albany Medical College, Albany, NY, USA). Cell lines were maintained for study in DMEM supplemented with $10 \%$ foetal bovine serum (FBS), in a $5 \% \mathrm{CO}_{2} / 95 \% \mathrm{O}_{2}$ incubator at $37^{\circ} \mathrm{C}$. Cells were placed in $0.25 \%$ serum-supplemented medium for 2 
days prior to treatment. The serum used for these studies was previously depleted of oestradiol by ion exchange resin, resulting in a total $\mathrm{E}_{2}$ concentration in undiluted serum of $<10^{-11} \mathrm{M}(\mathrm{Dr} \mathrm{Z}$ Cao, New York State Department of Health, Albany, NY, USA, personal communication). Oestradiol and resveratrol were obtained from the Sigma Chemical Company (St Louis, MO, USA), and ICI 182,780 was obtained from Tocris Cookson Inc. (Ellisville, MO, USA).

\section{Cell fractionation}

Fractionation and preparation of nucleoproteins was carried out according to our previously reported methods (Shih et al, 2001; Lin et al, 2002). Nuclear extracts were prepared by resuspension of the crude nuclei in hypotonic buffer with $420 \mathrm{mM} \mathrm{NaCl}, 20 \%$ glycerol at $4{ }^{\circ} \mathrm{C}$ with rocking for $1 \mathrm{~h}$, and the supernatants were collected after subsequent centrifugation at $4^{\circ} \mathrm{C}$ and $13000 \mathrm{rpm}$ for $10 \mathrm{~min}$.

\section{Immunoblotting}

The techniques are standard and have been previously described (Shih et al, 2001; Lin et al, 2002). Nucleoproteins were separated on discontinuous SDS-PAGE (9\% gels), and then transferred by electroblotting to Immobilon membranes (Millipore, Bedford, MA, USA). After blocking with $5 \%$ milk in Tris-buffered saline containing $0.1 \%$ Tween, the membranes were incubated overnight with polyclonal antibodies to phosphorylated ERK1/2, or serine 6(ser6-), ser15-, ser20- or ser392-phosphorylated p53 (Cell Signaling, Beverly, MA, USA). A polyclonal antibody to acetylated p53 was from Upstate Biotechnology (Lake Placid, NY, USA). The secondary antibody was goat anti-rabbit IgG (1:1000, Dako, Carpenteria, CA, USA). Immunoreactive proteins were detected by chemiluminescence (Amersham Life Science, Arlington Heights, IL, USA). All immunoblots were scanned and optical densities of bands were measured. Immunoblots shown in the figures are representative of three experiments. Statistical significance of changes in phosphorylation of ERKs 1 and 2, and of p53, as well as p53 acetylation, was calculated by one-way analysis of variance on data from three experiments. Molecular weight markers are included in Figure 1 for reference; band molecular weights are similar to those in Figure 1 in Figures 2-5.

\section{Electrophoretic mobility gel shift assay (EMSA)}

Nuclear extracts $(10 \mu \mathrm{g}$ protein) were incubated in a $25 \mu \mathrm{l}$ total

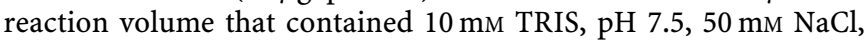
$1.0 \mathrm{mM} \mathrm{MgCl}_{2}, 0.5 \mathrm{~mm}$ EDTA, $0.5 \mathrm{~mm}$ DTT, 4\% glycerol and $0.05 \mu \mathrm{g} \mu \mathrm{l}^{-1}$ poly(dI-dC) (Promega, Madison, WI, USA). A p53binding oligonucleotide (Santa Cruz, Santa Cruz, CA, USA), labelled with $\left[{ }^{32} \mathrm{P}\right]$ by $\mathrm{T} 4$ polynucleotide kinase (Promega), was added to the total reaction mixture, which was then incubated for $20 \mathrm{~min}$ at room temperature. A control nonreactive SP-1 oligonucleotide (Promega) was prepared in the same manner. Samples were loaded on $4 \%$ polyacrylamide gels in low ionic strength buffer (22.3 mm Tris, $22.2 \mathrm{~mm}$ borate, $0.5 \mathrm{~mm}$ EDTA) and run with cooling at $15 \mathrm{~V} \mathrm{~cm}^{-1}$. The gels were then dried, exposed to $\mathrm{X}$-ray film and autoradiographs were analysed.

\section{$\mathrm{RT}$ - polymerase chain reaction (PCR)}

Total RNA was isolated as described previously (Shih et al, 2002). First-strand complementary DNAs were synthesised from $1 \mathrm{mg}$ of total RNA using oligo-deoxythymidine and AMV Reverse Transcriptase (Promega). First-strand cDNA templates were amplified for $p 21$ and GAPDH by PCR using a hot start (Ampliwax, Perkin Elmer, Foster City, CA, USA). Primer sequences were as previously
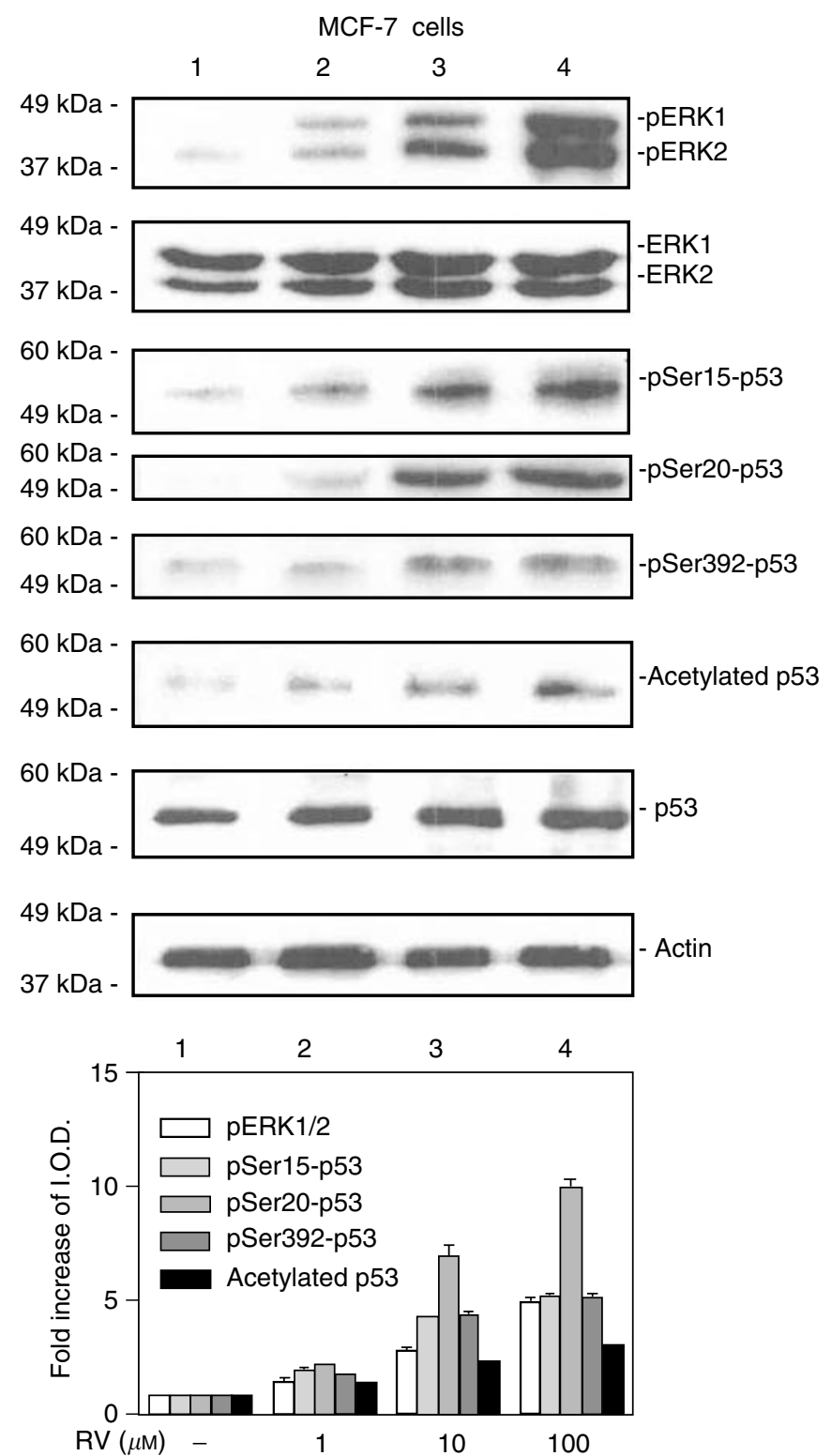

Figure I Resveratrol treatment of MCF-7 cells leads to phosphorylation (activation) of MAPK, serine phosphorylation of p53 and acetylation of p53 in MCF-7 breast cancer cells. Cells were treated with I - I00 $\mu$ M resveratrol (RV) for $4 \mathrm{~h}$. Nuclear proteins were separated by electrophoresis, and immunoblots performed with selected antibodies. Mitogen-activated protein kinase activation, shown as appearance in nuclei of nuclear phosphorylated ERKI and ERK2 (pERKI and 2), and phosphorylation of serines 15, 20 and 392 of $p 53$, as well as acetylation of $p 53$, were induced by resveratrol in a concentration-dependent manner (lanes $2-4$ ). Increases in phosphorylation of ERKI/2 and acetylation and phosphorylation of p53 with $1-100 \mu \mathrm{M} R V$ were each significant at $P<0.001$ by one-way analysis of variance in three similar experiments. The graph below shows the changes in phosphorylation of ERK I/2 and p53, and acetylation of p53, normalized to a value of I in control samples, in three experiments. Means \pm s.e.m. are shown. Immunoblots of total nuclear ERKs I and 2 (second panel from top) are consistent with activation (phosphorylation) and nuclear accumulation of these proteins, and a slight increase in total nuclear p53 is consistent with the resveratrol effect which we have previously described (Lin et al, 2002; Shih et al, 2002). Actin immunoblots serve as loading controls in this and subsequent figures. Immunoblots in all figures are representative of three or more experiments. Molecular weights of the proteins shown are as follows: pERKI, $44 \mathrm{kDa}$; pERK2, $42 \mathrm{kDa}$; p53, $53 \mathrm{kDa}$; actin, $43 \mathrm{kDa}$. (I.O.D., integrated optical density). 
A
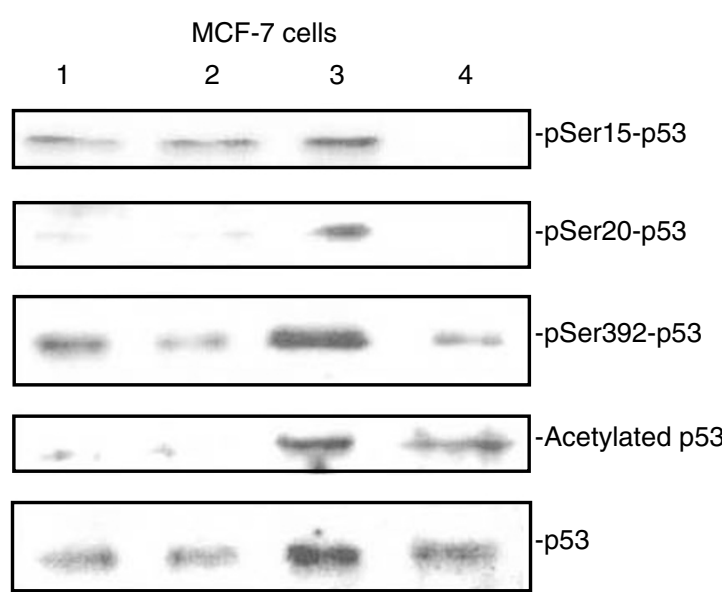

-p53
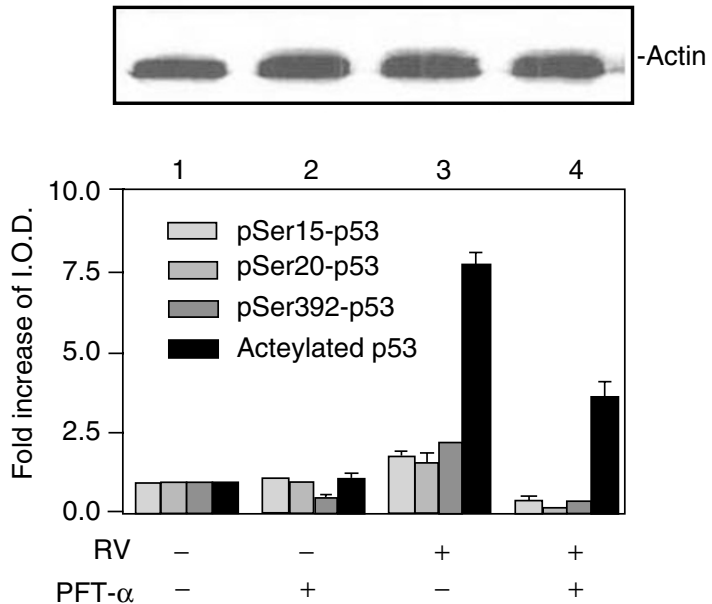

B

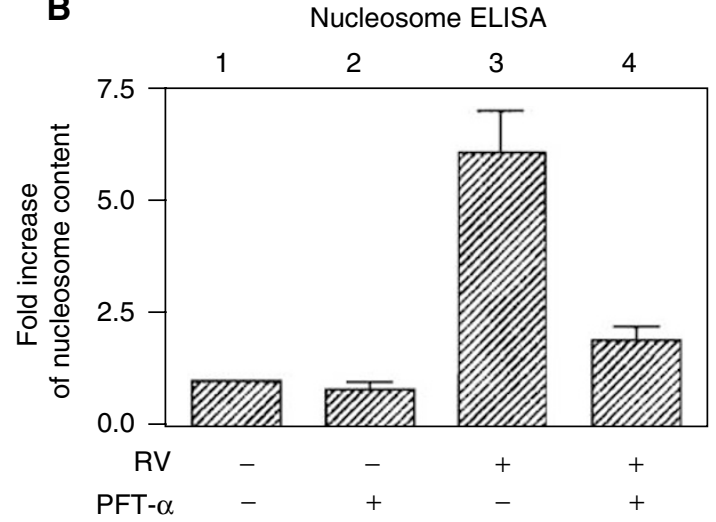

Figure 2 Activation of p53 and apoptosis induced by resveratrol is inhibited by pifithrin- $\alpha$ in MCF-7 cells. (A) Cells were treated with $10 \mu \mathrm{M}$ resveratrol (RV) for $4 \mathrm{~h}$ in the presence or absence of $20 \mu \mathrm{M}$ pifithrin- $\alpha$ (PFT- $\alpha$ ), a specific p53 inhibitor. As shown by immunoblots of nuclear fractions from a representative experiment above, and the accompanying graph below, resveratrol caused nuclear accumulation, serine phosphorylation and acetylation of p53 ( $P<0.05$ comparing lanes I and 3 for each parameter). Treatment with $\mathrm{PFT}-\alpha$ resulted in decreased phosphorylation and acetylation of p53 ( $P<0.05$ for all parameters, comparing lanes 3 and 4). Molecular weight markers in this figure are not shown, but are similar to those shown in Figure I. (B) Cells were treated with $10 \mu \mathrm{M}$ resveratrol for $24 \mathrm{~h}$ in the presence or absence of $20 \mu \mathrm{M}$ PFT- $\alpha$. Apoptosis, shown by an increase in nucleosome content determined by ELISA, occurred with resveratrol treatment $(P<0.001$, comparing lanes I and 3. Pifithrin- $\alpha$ had no effect alone, but significantly blocked resveratrol-induced apoptosis (comparing lanes 3 and $4, P<0.005$ ). Means \pm s.e.m. of six experiments are shown.
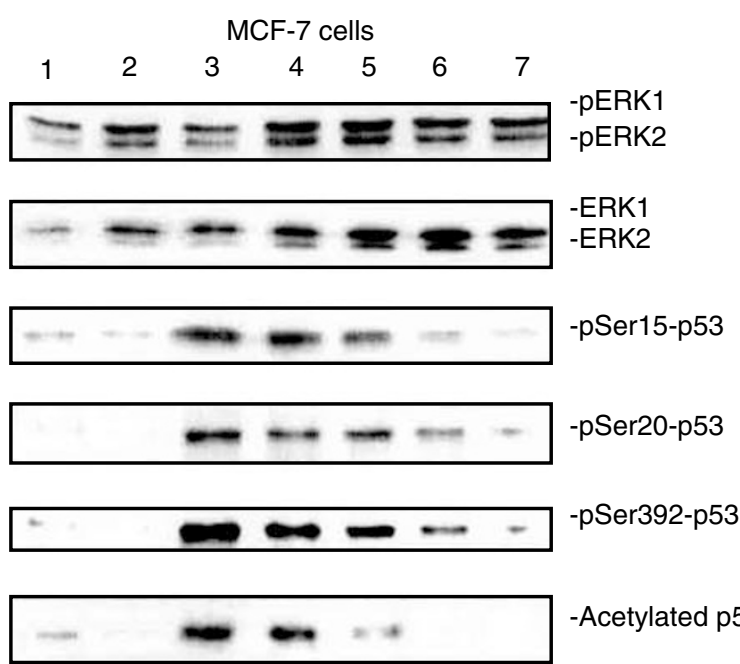

-Acetylated p53

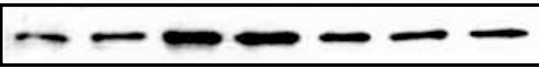

$-p 53$

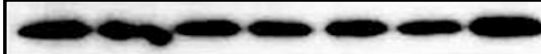

-Actin

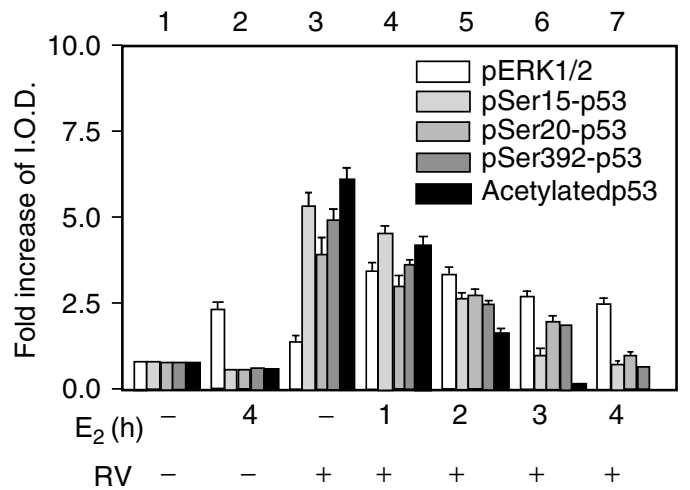

Figure $3 \quad E_{2}$ inhibition of resveratrol-induced activation of MAPK and p53 is time dependent. MCF-7 cells were treated with $E_{2}\left(10^{-9} \mathrm{M}\right)$ alone for $4 \mathrm{~h}$ or for different time periods $(0-4 \mathrm{~h})$ with resveratrol $(\mathrm{RV}, 10 \mu \mathrm{M}$, $4 \mathrm{~h})$, after which nuclear fractions were prepared from each sample. This series of immunoblots, representative of three experiments, indicates that minimal activation of $\mathrm{ERKI} / 2$ by resveratrol (top panel, lane 3) was enhanced by $\mathrm{I}-2 \mathrm{~h}$ incubation with $\mathrm{E}_{2}$ (lanes 4 and 5 ). A longer incubation with $E_{2}$ caused a time-dependent reduction in ERKI/2 phosphorylation (lanes $4-7, P<0.05)$. Resveratrol induced phosphorylation of serines 15 , 20 and 392 of p53 (pSer15-, pSer20- and pSer392-p53), and acetylation of p53 (lane 3 in each panel). However, these effects of resveratrol on p53 post-translational modification were progressively inhibited by coincubation with $E_{2}$ for $1-4 h$. The reductions in resveratrol-induced serine- 15 , serine20 , and serine-392 phosphorylation and acetylation of $p 53$ by $E_{2}$ were significant at $P<0.003$ or less. Molecular weight markers in this figure are not shown, but are similar to those shown in Figure I.

described (Shih et al, 2002). The PCR cycle was an initial step of $95^{\circ} \mathrm{C}$ for $3 \mathrm{~min}$ followed by $94^{\circ} \mathrm{C}$ for $1 \mathrm{~min}, 55^{\circ} \mathrm{C}$ for $1 \mathrm{~min}, 72^{\circ} \mathrm{C}$ for $1 \mathrm{~min}$, then 25 cycles and a final cycle of $72^{\circ} \mathrm{C}$ for $8 \mathrm{~min}$. Polymerase chain reaction products were subjected to electrophoresis in $2 \%$ agarose gels containing $0.2 \mu \mathrm{g} \mathrm{ml}^{-1}$ ethidium bromide. Gels were visualised under UV light and photographed with Polaroid film (Polaroid Co., Cambridge, MA, USA). Photographs were scanned under direct light (Bio-Image, Millipore) for quantitation and illustration. Results of p21 cDNA levels were normalised to $G A D P H$ cDNA levels from the same samples. 
A
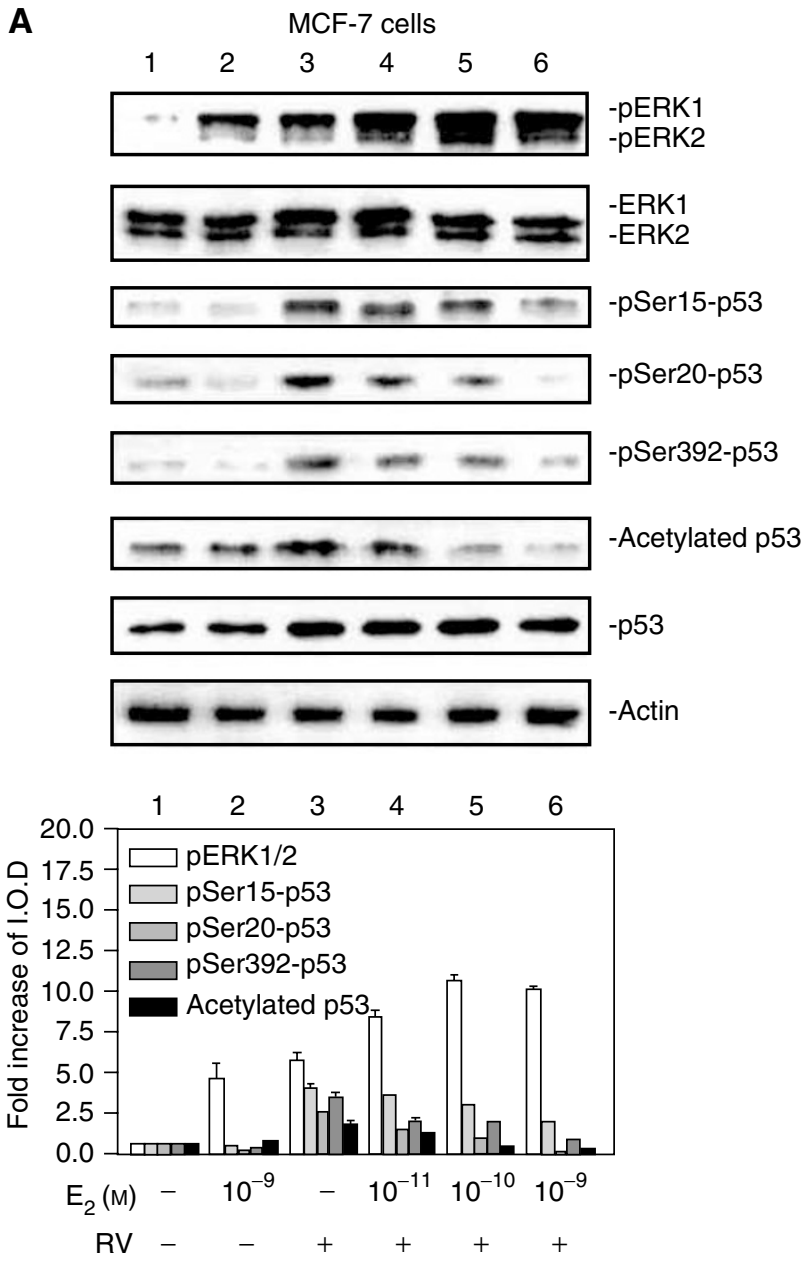

B

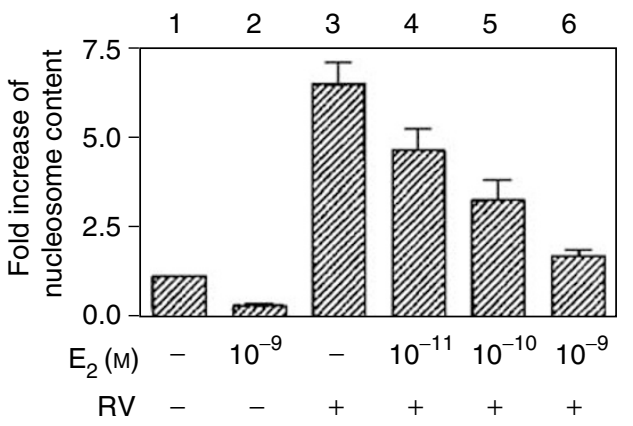

Figure $4 \quad E_{2}$ inhibits resveratrol-induced p53 phosphorylation and acetylation, and subsequent apoptosis, in a concentration-dependent manner. (A) MCF-7 cells were treated with $E_{2}\left(10^{-11}-10^{-9} \mathrm{M}\right)$ with or without resveratrol (RV, $10 \mu \mathrm{M}$ ) for $4 \mathrm{~h}$. Immunoblots of nuclear fractions from this representative experiment show that resveratrol-induced MAPK activation (pERKI/2, top panel, lane 3) was enhanced by $10^{-11}-10^{-9} \mathrm{ME}$ (lanes 3-6; $P<0.005)$. However, resveratrol-induced serl5, ser20 and ser392 phosphorylation of $\mathrm{p} 53$, as well as acetylation of $\mathrm{p} 53$, was inhibited by $E_{2}$ in a dose-dependent manner $(P<0.00 \mathrm{I}$, lanes $3-6$ for all these parameters), with the most marked inhibition occurring at $10^{-9} \mathrm{M} \mathrm{E}_{2}$ (lane 6). Molecular weight markers in this figure are not shown, but are similar to those shown in Figure I. (B) This graph shows the extent of apoptosis, measured by nucleosome ELISA, in MCF-7 cells treated with $\mathrm{E}_{2}\left(\mathrm{IO}^{-11}\right.$ $10^{-9} \mathrm{M}$ ) with or without resveratrol (RV, $\left.10 \mu \mathrm{M}\right)$ for $24 \mathrm{~h}$. Resveratrol alone caused apoptosis (lane 3, P<0.00I). E2 alone did not induce apoptosis, but the hormone inhibited nucleosome formation induced by resveratrol in a dose-dependent manner $(P<0.00 \mathrm{I})$. Means \pm s.e.m. of five experiments are shown.
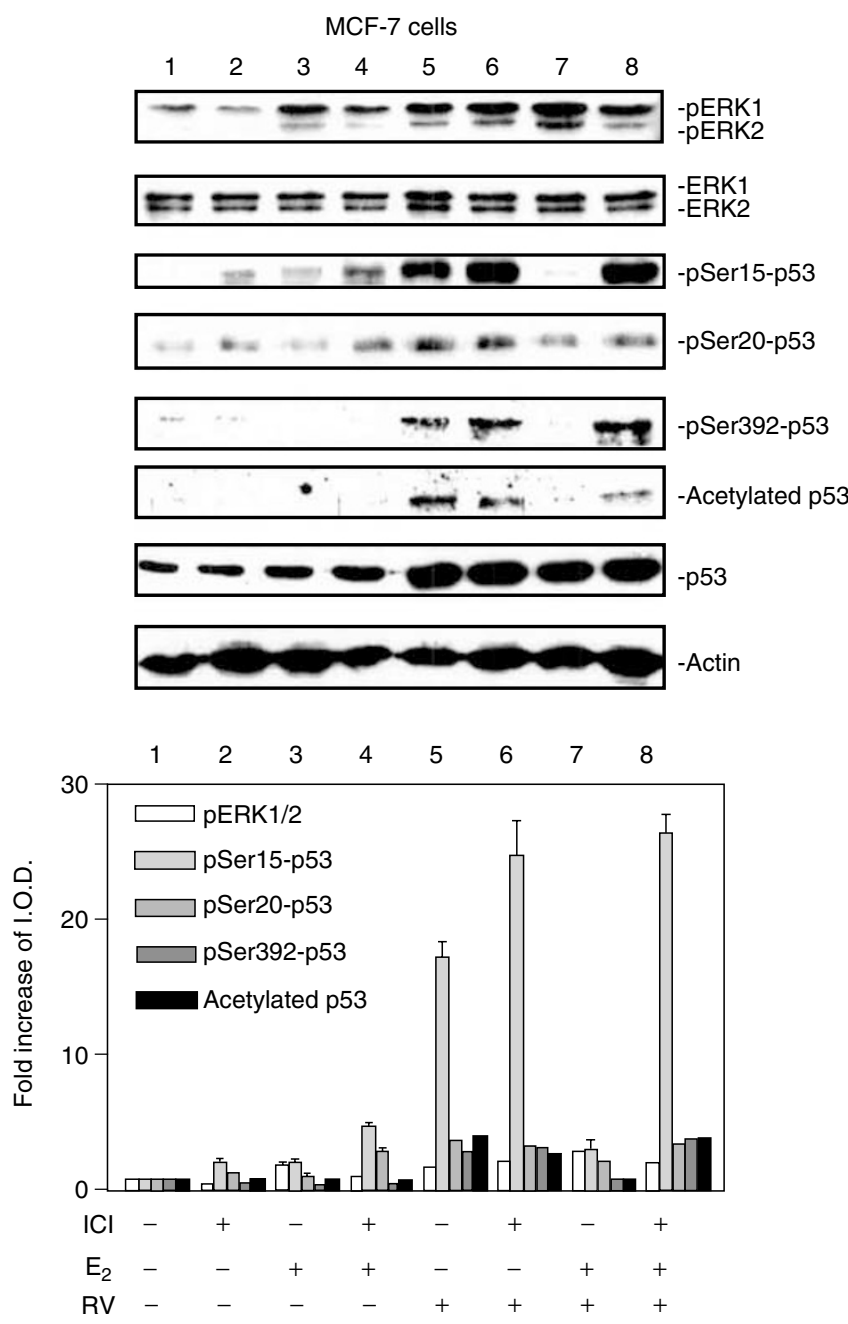

Figure $5 \mathrm{ICl} \mid 82,780(\mathrm{ICl})$ inhibits the effects of $E_{2}$ on resveratrolinduced activation of MAPK and p53. MCF-7 cells were pretreated with $3 \mathrm{nM} \mathrm{ICl}$ or diluent for $30 \mathrm{~min}$, after which they were treated with $10^{-9} \mathrm{ME}_{2}$ and/or $10 \mu \mathrm{M}$ resveratrol for $4 \mathrm{~h}$ along with continued $3 \mathrm{nM} \mathrm{ICl}$ or diluent as in the pretreatment period. Results shown are representative of three experiments. Immunoblots of nuclear fractions show that $\mathrm{ICl}$ minimally inhibited $E_{2}$-induced MAPK activation (comparing lanes 3 and 4), but did not inhibit resveratrol-induced MAPK activation (lanes 5 and 6 ). ICl 182,780 did enhance resveratrol-induced ser|5-p53 phosphorylation, although this effect was not statistically significant. The additive effect on MAPK activation of $E_{2}$ and resveratrol was reduced by $\mathrm{ICl}(P<0.05$, lane 7 vs lane 8 ), and the inhibitory effect of $E_{2}$ on resveratrol-induced serine phosphorylation and acetylation of p53 was partially reversed by $\mathrm{ICl}$ treatment $(P<0.02$ for each parameter, comparing lanes 7 and 8$)$. Molecular weight markers in this figure are not shown, but are similar to those shown in Figure I.

\section{Apoptosis/nucleosomes}

Cells were harvested and washed twice with phosphate-buffered saline. Nucleosome ELISA assays were carried out according to the protocol provided by Oncogene Research Products (Cambridge, MA, USA) (Lin et al, 2002).

\section{Apoptosis/DNA fragmentation}

Total genomic DNA was extracted according to the protocol of the SUICIDE-TRACK ${ }^{\mathrm{TM}}$ DNA LADDER ISOLATION KIT (Oncogene, Cambridge, MA, USA). DNA electrophoresis was performed in $1.5 \%$ agarose gels containing $0.2 \mu \mathrm{g} \mathrm{ml}^{-1}$ of ethidium bromide. 
Gels were visualised under UV light and photographed with Polaroid film (Polaroid Co., Cambridge, MA, USA). Photographs were scanned under direct light (BioImage, Millipore) for quantitation and illustration.

\section{RESULTS}

\section{Effects of resveratrol and a p53 inhibitor on MAPK activation, p53 phosphorylation and apoptosis in MCF-7 cells}

Initial studies focused on the effects of resveratrol on phosphorylation, or activation, of MAPK (pERK1/2) and p53, and accumulation of these phosphorylated proteins in nuclear fractions of MCF-7 cells (Figure 1). Treatment of these cells with $1-100 \mu \mathrm{M}$ resveratrol for $4 \mathrm{~h}$ induced MAPK phosphorylation and serine phosphorylation of p53 at residues 15, 20 and 392. In addition, acetylation of p53 was induced by resveratrol treatment (Figure 1). Phosphorylation of ERK1 and ERK2, and of p53, resulted in translocation of these proteins to cell nuclei. The combined results from three experiments, normalised to a value of 1 in control samples, are shown in the graph of Figure 1.

In order to determine if resveratrol-induced apoptosis was p53 dependent, a specific p53 inhibitor, pifithrin- $\alpha$ (PFT- $\alpha$ ) (Komarov et al, 1998), was added to cells in the presence or absence of resveratrol. Resveratrol-induced phosphorylation of serines 15, 20 and 392, and acetylation of p53, were inhibited by PFT- $\alpha$ (Figure 2A). In Figure 2B, the combined results of three nucleosome ELISA studies show a five-fold increase in nucleosome content in cells treated with resveratrol, and a reduction in the resveratrol effect with PFT- $\alpha$. Increased nucleosome content is directly related to apoptosis (Lin et al, 2002; Shih et al, 2002). These findings indicate that resveratrol-induced apoptosis in MCF7 cells is p53-dependent.

\section{Effect of oestradiol on resveratrol-induced MAPK activation, serine phosphorylation of p53 and apoptosis}

In a $4 \mathrm{~h}$ study with MCF-7 cells, $\mathrm{E}_{2}\left(10^{-9} \mathrm{M}\right)$ caused phosphorylation (activation) and nuclear translocation of MAPK, shown as pERK1 and pERK2 in Figure 3, lane 2. Furthermore, in cells treated with $10 \mu \mathrm{M}$ resveratrol for $4 \mathrm{~h}, 1-4 \mathrm{~h}$ of $\mathrm{E}_{2}$ exposure enhanced the activation and nuclear translocation of MAPK caused by resveratrol (lanes 4-7 compared with lane 3). In contrast to this enhancement by $E_{2}$ of resveratrol-induced MAPK activation, the hormone inhibited resveratrol-induced serine phosphorylation of p53 in a time-dependent manner. Phosphorylation of serines 15, 20 and 392 by resveratrol, as well as acetylation of p53, were all progressively reduced in resveratrol-treated MCF-7 cells by the addition of $\mathrm{E}_{2}$ to resveratrol for 1-4h.

In $\mathrm{E}_{2}$ concentration-response studies, there was hormone concentration-dependent enhancement of resveratrol-stimulated MAPK activation with $10^{-11}-10^{-9} \mathrm{M} \mathrm{E}_{2}$ (Figure 4A, lanes 4-6) but reduction in resveratrol-induced phosphorylation of $\mathrm{p} 53$ serines 15,20 and 392, and reduction in acetylation of p53 after treatment with both agents for $4 \mathrm{~h}$ (lanes 4-6). These latter effects were also $\mathrm{E}_{2}$ concentration-dependent. The effect of $10^{-11}-10^{-9} \mathrm{M} \mathrm{E}_{2}$ on resveratrol-induced apoptosis in MCF-7 cells, indicated by nucleosome ELISA, is shown in Figure 4B. Dose-responsive inhibition by $\mathrm{E}_{2}$ of apoptosis in these resveratrol-treated cells correlates directly with the reduction in post-translational modification of p53 seen in Figure 4A, above.

\section{Effect of the oestrogen receptor- $\alpha$ (ER) inhibitor, ICI 182,780 , on actions of resveratrol and oestradiol}

$\mathrm{E}_{2}$ has been shown to block chemotherapy- or radiation-induced apoptosis through a plasma membrane receptor that appears to be the nuclear ER located in the cell membrane (Razandi et al, 2000). Therefore, we tested the $\mathrm{E}_{2}$ effect on resveratrol action in the presence of ICI 182,780 (ICI), an inhibitor of ER (Papaconstantinou et al, 2002). ICI 182,780 partially suppressed $\mathrm{E}_{2}$-induced ERK1/2 phosphorylation, or activation (Figure 5, comparing lanes 3 and 4). ICI 182,780 did not inhibit resveratrol-induced posttranslational modifications of p53 (lane $5 v s$ lane 6). ICI 182,780 did enhance the effect of resveratrol on serine-15 phosphorylation of p53 (lane 6), although this effect was not statistically significant. $\mathrm{E}_{2}$ blocked serine phosphorylation and acetylation of p53 caused by resveratrol (lane 7), but in the presence of $E_{2}$ and ICI, the inhibitory effect of the hormone on phosphorylation and acetylation of p53 was not seen (lane 8). In summary, signal transduction by resveratrol was enhanced by ICI, and the action on MAPK activation by $E_{2}$ alone was inhibited by ICI. The inhibitory effect of $\mathrm{E}_{2}$ on resveratrol-induced phosphorylation and acetylation of p53 appears to be ER-mediated, in that this hormone effect was reversed by the ER inhibitor.

\section{Oestradiol inhibits resveratrol-induced p53 binding to DNA and p53-dependent gene expression}

We studied the interaction of p53 with a p53-binding radiolabelled oligonucleotide added to nuclear extracts from resveratrol-treated cells, in the presence or absence of $E_{2}$. Results shown in Figure 6 indicate that (1) resveratrol caused binding of p53 to the labelled oligonucleotide, and (2) $\mathrm{E}_{2}$ inhibited interaction of p53 and the oligonucleotide. Therefore, $\mathrm{E}_{2}$ not only inhibits resveratrolinduced post-translational modification of p53 as shown above in Figures 3-5 but also inhibits DNA binding by p53.

Resveratrol is known to induce p53-dependent $p 21$ expression in human thyroid cancer cells (Shih et al, 2002), an effect that is associated with apoptosis in these cells. Induction by resveratrol of p21 expression in MCF-7 cells has been previously shown to lead to apoptosis (Pozo-Guisado et al, 2002). In our studies of transcription by RT - PCR in MCF-7 cells, we found that resveratrol caused transcription of $p 21$, and that $\mathrm{E}_{2}$ inhibited this action of the

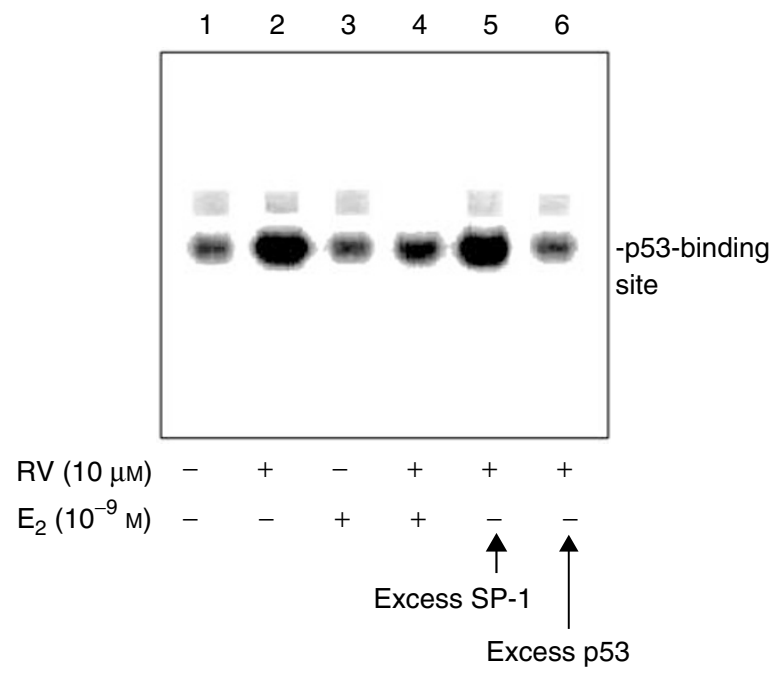

Figure $6 \quad E_{2}$ inhibits resveratrol-induced p53 binding to a relevant oligonucleotide in an EMSA. The assay was carried out with nuclear fractions prepared after $4 \mathrm{~h}$ treatment of cells with $10 \mu \mathrm{M}$ resveratrol, $10^{-9} \mathrm{M} \mathrm{E}_{2}$, or both agents. $\mathrm{p} 53$ binding to the radiolabelled oligonucleotide was seen (lane 2). $E_{2}$ inhibited p53 binding (lane 4 compared with lane 2) Excess unlabelled oligonucleotide (p53-oligo) decreased p53 binding to the labelled form (lane 6), whereas there was no change in p53 binding with an excess of unlabelled nonspecific SP-I oligonucleotide (lane 5). This figure is representative of three similar experiments. 
A
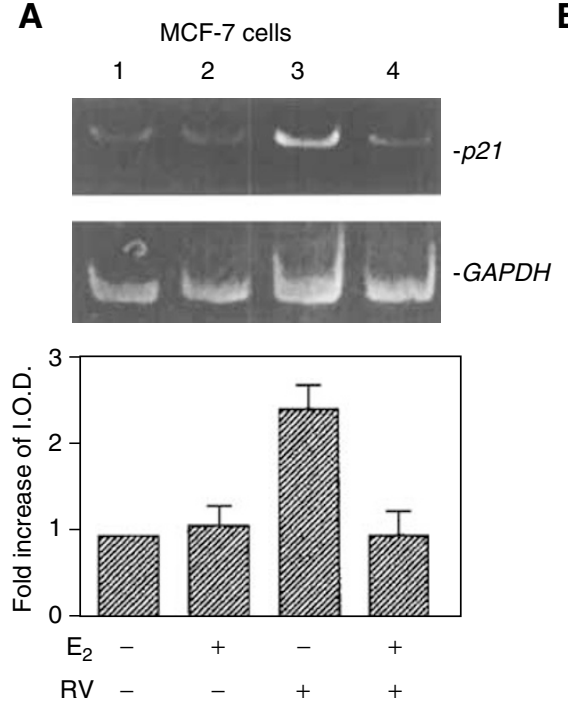

Figure $7 \quad E_{2}$ inhibits p53-inducible $p 21$ expression and apoptosis caused by resveratrol. (A) MCF-7 cells were treated with $10 \mu \mathrm{M}$ resveratrol in the presence or absence of $10^{-9} \mathrm{ME}_{2}$ for $24 \mathrm{~h}$. Based on measurement of $\mathrm{p} 21$ and GAPDH cDNA band densities (upper and lower images, respectively), and correction of $p 21$ densities for the levels of GAPDH, a 2.5-fold increase in p2I cDNA abundance was seen with resveratrol treatment (lane 3 compared with lane I). This increase in p21 expression was significant $(P<0.025)$ by analysis of variance. $E_{2}, 10^{-9} \mathrm{M}$, blocked $p 21$ transcription induced by resveratrol (lane 4 compared with lane $3, P<0.05$ ), but had no effect in the absence of resveratrol. (B) MCF-7 cells were treated with $10 \mu \mathrm{M}$ resveratrol in the presence or absence of $10^{-9} \mathrm{M} \mathrm{E}_{2}$ for $24 \mathrm{~h}$. Resveratrol caused DNA fragmentation, indicating apoptosis as shown in this representative figure (lane 3 ). This effect of resveratrol was inhibited by $E_{2}$ (lane 4).

stilbene (Figure 7A). The biological end point of this effect of $E_{2}$ was inhibition of resveratrol-induced apoptosis, as indicated by loss of DNA fragmentation (Figure 7B) and nucleosome ELISA (Figure 4B).

Oestradiol, $10^{-9} \mathrm{M}$, had no effect alone on $p 21$ expression in our experiments. Cariou et al (2000) have described a transient increase in $p 21$ content after $4 \mathrm{~h}$ treatment with $10^{-8} \mathrm{M} \mathrm{E}_{2}$ in MCF-7 cells, whereas in our studies, a lower concentration of hormone was used for $24 \mathrm{~h}$. Others have reported that $\mathrm{E}_{2}$ can enhance abundance of p21 mRNA in D351 breast cancer cells (Levenson et al, 2003). The basis for these disparate effects of $\mathrm{E}_{2}$ is not clear, although differences in cell lines, in hormone concentration or in exposure time of cells to $\mathrm{E}_{2}$ (Levenson et al, 2003) may have contributed to the different results. The D351 cells used by Levenson and co-workers were MDA-MB-231 cells transfected with cDNA for $w t$ ER, but the p53 in these cells is said to be nonfunctional (Toillon et al, 2002).

\section{DISCUSSION}

Resveratrol, a phyto-oestrogen based on the fact that it binds to and activates ER, has similar affinity for $\mathrm{ER} \alpha$ and $\mathrm{ER} \beta$, but with 7000-fold lower affinity than $\mathrm{E}_{2}$ (Bowers et al, 2000). As has been shown for other selective ER modulators such as tamoxifen, resveratrol has been considered to have potential as an anti-breast cancer adjunct (Bhat et al, 2001). The stilbene has been shown to inhibit carcinogen-induced preneoplastic lesions and mammary tumours in rodent models (Bhat et al, 2001). In the present studies, treatment of MCF-7 breast cancer cells with 1-100 $\mu \mathrm{M}$ resveratrol induced MAPK activation, serine phosphorylation and acetylation of p53 and p53-dependent apoptosis. In addition to these findings in breast cancer cells, we have previously shown that human thyroid and prostate cancer cells are susceptible to resveratrolinduced, p53-dependent apoptosis (Lin et al, 2002; Shih et al, 2002).

We have examined the possibility that the actions of resveratrol on MCF-7 cells might be modified by $\mathrm{E}_{2}$. Acting at the cell surface, oestradiol has been shown by several investigators to rapidly activate MAPK (Migliaccio et al, 1996; Razandi et al, 2003; Wade and Dorsa, 2003). We have confirmed this action of $\mathrm{E}_{2}$ in MCF-7 cells in this report (Figures 3-5). Mitogen-activated protein kinase activation induced by oestrogen in breast cancer cells has been linked to cell proliferation but there have been no reports to indicate that MAPK activation in breast cancer cells is involved in apoptosis (Santen et al, 2002). In our studies, treatment of MCF-7 cells with $10 \mu \mathrm{M}$ resveratrol in the presence of $10^{-9} \mathrm{M} \mathrm{E}_{2}$ produced additive MAPK activation by $\mathrm{E}_{2}$ and resveratrol. However, $\mathrm{E}_{2}$ inhibited resveratrol-induced phosphorylation of serines 6,15 and 392 in p53, as well as acetylation of p53, despite the enhancement by $\mathrm{E}_{2}$ of MAPK activity.

A downstream effect of this action of oestrogen on MAPK activation may be phosphorylation of Ser-118 of ER $\alpha$ and enhanced transcriptional activity of the receptor (Kato et al, 1995). We did not observe apoptosis as a downstream consequence of MAPK activation by $\mathrm{E}_{2}$ alone, compared with the actions of resveratrol. Thus, the confluence at MAPK of signals generated by resveratrol and $\mathrm{E}_{2}$ results, downstream of MAPK, in a divergence of effects on nuclear transcription by $\mathrm{p} 53$ and by $\mathrm{E}_{2}$. This is consistent with the existence of discrete intracellular pools of MAPK (ERK1/2) separately regulated by resveratrol and $E_{2}$.

The antiapoptotic effect of $E_{2}$ in the presence of resveratrol involves rapid stimulation of signalling cascades, including the ERK1/2 pathway. In our studies, the ER inhibitor ICI 182,780 suppressed both $\mathrm{E}_{2}$-induced MAPK activation and the inhibitory effect of $E_{2}$ on resveratrol-induced serine phosphorylation of p53. Although resveratrol has been shown by others to have oestrogenlike activity in a transcriptional assay in cells expressing predominantly ER $\alpha$ (Bhat et al, 2001), we found that ICI 182,780, in a relatively low concentration of $3 \mathrm{nM}$, did not diminish resveratrol-induced activation of MAPK and serine phosphorylation of p53, and in fact appeared to enhance these effects of the stilbene. The concentration we used was similar to the inhibitory $10 \mathrm{~nm}$ concentration used in MCF-7 cells by Cariou et al (2000).

Others have also reported that activities of resveratrol are not affected by ICI 182,780 (Cho et al, 2002). Since $\mathrm{E}_{2}$ action was inhibited by ICI 182,780 in our studies, while resveratrol activity was minimally affected by ICI 182,780 , the inhibitory effect of $E_{2}$ on resveratrol-induced serine phosphorylation of p53 was interpreted to be ER mediated. Studies by others have shown that ICI 182,780 may enhance the effects of doxorubicin, paclitaxol and tumour necrosis factor- $\alpha$ on the production of apoptosis in MCF-7 cells (Burow et al, 2001).

Oestradiol alone had no effect on the binding of p53 to a relevant oligonucleotide. However, $\mathrm{E}_{2}$ did inhibit resveratrolinduced binding of p53 to the oligonucleotide (Figure 6). This finding is consistent with $\mathrm{E}_{2}$ inhibition of post-translational modifications of p53 that are essential for p53-dependent gene transcription. These results have implications for the possible use of resveratrol therapeutically in cancer treatment, as they suggest that resveratrol may be most effective in an oestrogen-depleted environment.

The transcriptional activity of $\mathrm{p} 53$ is subject to modulation by other hormones as well. For example, glucocorticoids prevent p53induced apoptosis through interaction of the glucocorticoid receptor (GR) with p53 and the E3 ubiquitin ligase, Hdm2 (Sengupta and Wasylyk, 2001) in cytosol. Another example of a modulator is the mdm2 gene that is positively regulated by $\mathrm{p} 53$, yet the $\mathrm{mdm} 2$ protein binds $\mathrm{p} 53$, forming a feedback loop that controls mdm2 activity (Qi et al, 1999). 
Since the effect of resveratrol that we have demonstrated in MCF-7 cells centres on the modification and action of the tumour suppressor $\mathrm{p} 53$, it is conceivable that cancer cells harbouring mutant p53 might not respond in the same manner. However, studies by Hsieh et al (1999) have documented resveratrol-induced reduction in growth of MDA-MB-435 cells, which contain a mutant p53. In our studies of the actions of resveratrol on DU145 prostate cancer cells, which also contain mutant p53 (Zhang et al, 2003), resveratrol did induce apoptosis. Future studies are to be directed towards the identification of critical sites on p53 for resveratrol action.

The present studies indicate that ambient $\mathrm{E}_{2}$ may antagonise actions of resveratrol in selected treatment paradigms. Our results suggest the complexity of actions of resveratrol in both in vivo and in vitro settings. Were resveratrol to be tested in intact animals, it would be important to control for levels of oestrogen, and useful to examine actions of the stilbene in the presence of an $\mathrm{E}_{2}$ antagonist.

\section{ACKNOWLEDGEMENTS}

This work has been supported by grants from the Research Service, United States Department of Veterans Affairs, and from the Charitable Leadership, Candace King Weir and Beltrone Foundations.

\section{REFERENCES}

Agarwal ML, Taylor WR, Chernov MV, Chernova OB, Stark GR (1998) The p53 network. J Biol Chem 273: 1 -4

Ashcroft M, Vousden KH (1999) Regulation of p53 stability. Oncogene 18: $7637-7643$

Berlev NA, Liu L, Chehab NH, Mansfield K, Harris KG, Halazonetis TD, Berger SL (2001) Acetylation of p53 activates transcription through recruitment of coactivators/histone acetytransferases. Mol Cell 8: $1243-1254$

Bhat KP, Lantvit D, Christov K, Mehta RG, Moon RC, Pezzuto JM (2001) Estrogenic and antiestrogenic properties of resveratrol in mammary tumor models. Cancer Res 61: $7456-7463$

Bowers JL, Tyulmenkov VV, Jernigan SC, Klinge CM (2000) Resveratrol acts as a mixed agonist/antagonist for estrogen receptors $\alpha$ and $\beta$. Endocrinology 141: $3657-3667$

Burow ME, Weldon CB, Tang Y, McLachlan JA, Beckman BS (2001) Oestrogen-mediated suppression of tumour necrosis factor alphainduced apoptosis in MCF-7 cells: subversion of Bcl-2 by anti-oestrogens. J Steroid Biochem Mol Biol 78: 409-418

Cariou S, Donovan JC, Flanagan WM, Milic A, Bhattacharya N, Slingerland JM (2000) Down-regulation of p21WAF1/CIP1 or p27Kip1 abrogates antiestrogen-mediated cell cycle arrest in human breast cancer cells. Proc Natl Acad Sci USA 97: $9042-9046$

Cho DI, Koo NY, Chung WJ, Kim TS, Ryu SY, Im SY, Kim KM (2002) Effects of resveratrol-related hydroxystilbenes on the nitric oxide production in macrophage cells: structural requirements and mechanism of action. Life Sci 71: 2071-2082

Clement M-V, Hirpara JL, Chawdhury S-H, Pervaiz S (1998) Chemopreventive agent resveratrol, a natural product derived from grapes, triggers CD95 signaling-dependent apoptosis in human tumor cells. Blood 92: 996- 1002

Higashimoto Y, Saito S, Tong XH, Hong A, Sakaguchi K, Appella E, Anderson CW (2000) Human p53 is phosphorylated on serines 6 and 9 in response to DNA damage-inducing agents. J Biol Chem 275: $23199-23203$

Hsieh TC, Burfeind P, Laud K, Backer JM, Traganos F, Darzynkiewicz Z, Wu JM (1999) Cell cycle effects and control of gene expression by resveratrol in human breast cancer cell lines with different metastatic potentials. Int J Oncol 15: $245-252$

Huang C, Ma WY, Goranson A, Dong Z (1999) Resveratrol suppresses cell transformation and induces apoptosis through a p53-dependent pathway. Carcinogenesis 20: $237-242$

Jang M, Cai L, Udeani GO, Slowing KV, Thomas CF, Beecher CW, Fong HH, Farnsworth NR, Kinghorn AD, Mehta RG, Moon RC, Pezzuto JM (1997) Cancer chemopreventive activity of resveratrol, a natural product derived from grapes. Science 275: $218-220$

Jeanet P, Bessis R, Gautheron B (1991) The production of resveratrol (3,5,4'-trihydroxystilbene) by grape berries in different stages. Am J Enol Viticul 42: $41-46$

Kato S, Endoh H, Masuhiro Y, Kitamoto T, Uchiyama S, Susaki H, Masushige S, Gotoh Y, Nishida E, Kawashima H, Metzger D, Chambon P (1995) Activation of the estrogen receptor through phosphorylation by mitogen-activated protein kinase. Science 270: 491 - 1494

Komarov PG, Komarova EA, Kondratov RV, Christov-Tselkov K, Coon JS, Chernov MV, Gudkov AV (1998) A chemical inhibitor of p53 that protects mice from the side effects of cancer therapy. Science 285: $1733-1737$

Levenson AS, Gehm BD, Pearce ST, Horiguchi J, Simons LA, Ward III JE, Jameson JL, Jordan VC (2003) Resveratrol acts as an estrogen receptor (ER) agonist in breast cancer cells stably transfected with ER alpha. Int J Cancer 104: $587-596$

Lin H-Y, Shih A, Davis FB, Tang H-Y, Martino LJ, Bennett JA, Davis PJ (2002) Resveratrol-induced serine phosphorylation of p53 causes apoptosis in a mutant p53 prostate cancer cell line. J Urol 168: $748-755$

Liu L, Scolnick DM, Trievel RC, Zhang HB, Marmorstein R, Halazonetis TD, Berger SL (1999) p53 sites acetylated in vitro by PCAF and p300 are acetylated in vivo in response to DNA damage. Mol Cell Biol 19: $1202-1209$

Lu R, Serrero G (1999) Resveratrol, a natural product derived from grape, exhibits antiestrogenic activity and inhibits the growth of human breast cancer cells. J Cell Physiol 179: $297-304$

Migliaccio A, Di Domenico M, Castoria G, de Falco A, Bontempo P, Nola E (1996) Tyrosine kinase/p21ras/MAP-kinase pathway activation by estradiol-receptor complex in MCF-7 cells. EMBO J 15: $1292-1300$

Pace-Asciak C, Hahn R, Diamandis EP, Soleas G, Goldberg DM (1995) The red wine phenolics trans-resveratrol and quercetin block human platelet aggregation and eicosanoid synthesis: Implications for protection against coronary disease. Clin Chim Acta 235: $207-219$

Papaconstantinou AD, Umbreit TH, Goering PL, Brown KM (2002) Effects of 17 alpha-methyltestosterone on uterine morphology and heat shock protein expression are mediated through estrogen and androgen receptors. J Steroid Biochem Mol Biol 82: 305-314

Pozo-Guisado E, Alvarez-Barrientos A, Mulero-Navarro S, Santiago-Josefat B, Fernandez-Salguero PM (2002) The antiproliferative activity of resveratrol results in apoptosis in MCF-7 but not in MDA-MB-231 human breast cancer cells: cell-specific alteration of the cell cycle. Biochem Pharmacol 64: 1375-1386

Prives C, Manley JL (2001) Why is p53 acetylated? Cell 107: 815-818

Qi JS, Yuan Y, Desai-Yajnik V, Samuels HH (1999) Regulation of the mdm2 oncogene by thyroid hormone receptor. Mol Cell Biol 19: 864-872

Razandi M, Alton G, Pedram A, Ghonshani S, Webb P, Levin ER (2003) Identification of a structural determinant necessary for the localization and function of estrogen receptor $\alpha$ at the plasma membrane. Mol Cell Biol 23: $1633-1646$

Razandi M, Pedram A, Levin ER (2000) Plasma membrane estrogen receptors signal to antiapoptosis in breast cancer. Mol Endocrinol 14: $1434-1447$

Sakaguchi K, Herrera JE, Saito S, Miki T, Bustin M, Vassilev A, Anderson CW, Appella E (1998) DNA damage activates p53 through a phosphorylation - acetylation cascade. Genes Dev 12: $2831-2841$

Santen RJ, Song RX, McPherson R, Kumar R, Adam L, Jeng MH, Yue W (2002) The role of mitogen-activated protein (MAP) kinase in breast cancer. J Steroid Biochem Mol Biol 80: 239-256

Sengupta S, Wasylyk B (2001) Ligand-dependent interaction of the glucocorticoid receptor with p53 enhances their degradation by $\mathrm{Hdm} 2$. Genes Dev 15: $2367-2380$

She QB, Bode AM, Ma WY, Chen NY, Dong Z (2001) Resveratrol-induced activation of p53 and apoptosis is mediated by extracellular-signalregulated protein kinases and p38 kinase. Cancer Res 61: 1604-1610 
Shih A, Davis FB, Lin H-Y, Davis PJ (2002) Resveratrol induces apoptosis in thyroid cancer cell lines via a mitogen-activated protein kinase- and p53dependent mechanism. J Clin Endo Metab 87: 1223-1232

Shih A, Lin HY, Davis FB, Davis PJ (2001) Thyroid hormone promotes serine phosphorylation of $\mathrm{p} 53$ by mitogen-activated protein kinase. Biochemistry 40: $2870-2878$

Toillon RA, Chopin V, Jouy N, Fauquette W, Boilly B, Le Bourbis X (2002) Normal breast epithelial cells induce p53-dependent apoptosis and p53independent cell cycle arrest of breast cancer cells. Breast Cancer Res Treat 71: $269-280$
Wade CB, Dorsa DM (2003) Estrogen activation of cyclic adenosine 5'monophosphate response element-mediated transcription requires the extracellularly regulated kinase/mitogen-activated protein kinase pathway. Endocrinology 144: $832-838$

Zhang Z, Li M, Wang H, Agrawal S, Zhang R (2003) Antisense therapy targeting MDM2 oncogene in prostate cancer: effects on proliferation, apoptosis, multiple gene expression, and chemotherapy. Proc Natl Acad Sci USA 100: $11636-11641$ 